Photovoltaic

https://doi.org/10.52825/thwildauensp.v1i.4

(C) Authors. This work is licensed under a Creative Commons Attribution 4.0 International License

Published: 15 June 2021

\title{
Design and implementation of a photovoltaic characterization platform at FaST
}

\author{
Moudjibatou AFODA ${ }^{1}$, N'detigma KATA ${ }^{1,2}$, Dambé. DOUTI ${ }^{1}$, Hodo-Abalo SAMAH ${ }^{1}$, Amadou \\ Séidou MAIGA ${ }^{2}$ \\ ${ }^{1}$ Faculté des Sciences et Techniques (FaST), Université de Kara, Togo \\ ${ }^{2}$ Laboratoire d'Électronique Informatique Télécommunication et Énergies Renouvelables, Université \\ Gaston Berger, 32000 Saint-Louis, Sénégal
}

\begin{abstract}
The site that houses the FaST faces high dusty winds and considerable temperature variation. Weather conditions such as solar radiation, temperature, and wind speed greatly affect the performance of PV modules. But the data from PV equipment manufacturers do not allow for proper sizing. Therefore, a rigorous study is needed to find the most suitable PV module technology for the study area. For this purpose, platforms for the acquisition of meteorological parameters and module characterization are indispensable. This platform project at FaST will serve training and pedagogy because its configuration will allow master and bachelor students to carry out practical work, to carry out studies on new cell technologies under the influence of external factors specific to the sub-Saharan zone and will bring an added value by providing additional information on real conditions and especially the influence of local external factors. Our study consisted first of all in the realization of the platform on the roof of the FaST, then in the design and the programming of a module of acquisition of the measured parameters on the basis of the Arduino microcontroller card and finally in the test of characterization of the modules used for the platform thanks to an electronic load on the basis of MOSFET of power controlled by a microcontroller that we realized.
\end{abstract}

Keywords: platform, acquisition, electronic load.

\section{Introduction}

The performance of PV modules is highly dependent on weather conditions such as solar radiation, temperature and wind speed. To provide energy continuously over a long period of time, a PV system must be correctly dimensioned. This requires a fairly rigorous study in order to make the right choice. To do this, platforms for acquiring meteorological parameters and characterizing the panels are indispensable. This platform project at the FaST will achieve the following objectives: the platform at the service of training and pedagogy: with the instantaneous taking of measurements, the platform will allow learners and visitors to observe the behavior of the modules according to the conditions in which the modules are located. Its configuration will allow practical work to be carried out without influencing the long-term measurements. Thus, master and bachelor students will be able to carry out their practical work. The platform at the service of research: In the research of photovoltaic technologies best adapted to the sub-Saharan zone, the platform will allow to realize studies on new cell technologies with the influence of external factors specific to the sub-Saharan zone. The PV modules sold to the local market can be characterized through this platform to reassure investors and customers. The platform at the service of projects: most projects in the northern part of Togo are based on software data that may not correspond to the reality on the ground. This platform will bring an added value by providing additional information on real conditions and especially the influence of local external factors. Our work consisted in 
the realization of the platform on the roof of the Faculty of Sciences and Technologies (FaST), then in the design of a variable electronic load based on MOSFET and finally in the design, the realization and the programming of the acquisition module based on the Arduino microcontroller.

\section{Methodology}

We have defined the parameters that must be acquired by making a bibliographic study. During a visit to meteorological centers, we noticed that the available data are the ambient temperature, relative humidity, wind speed and direction. These centers do not acquire solar irradiation. From these researches, we have established a list of materials [1] of the platform and the right way to make their different assemblies. We have thus realized a diagram presenting in a general way the platform.

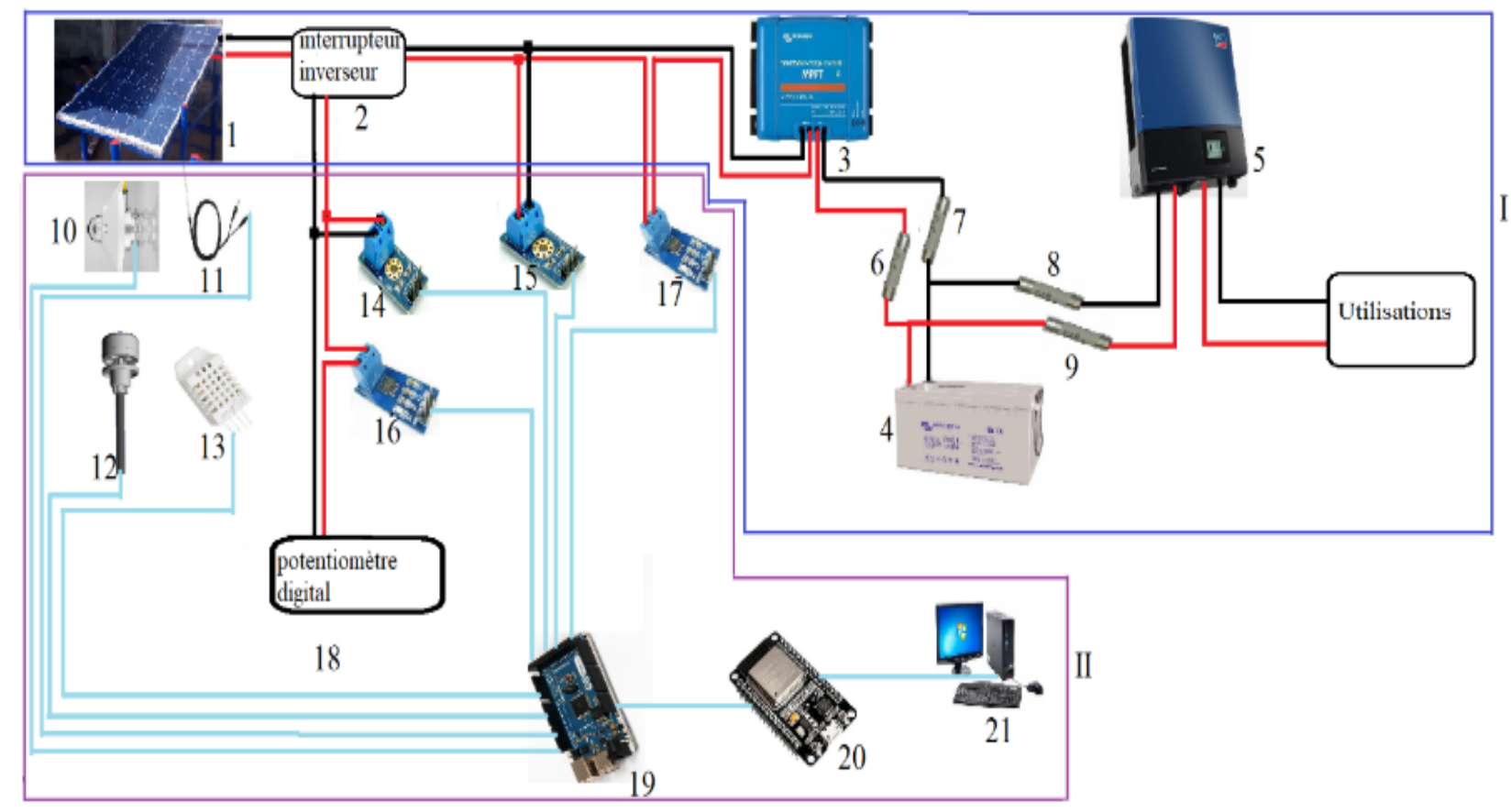

Figure 1: Schematic of the whole system

I-Power block

1-Solar modules

2-Inverter switch

3-Regulator

4- Battery

5- Inverter

6-7-8-9-Fuses
II-Acquisition block

10-Pyranometer

11-Temperature sensor

12-Wind vane-anemometer

13- DHT22 sensor

14-15- Voltage sensors

16-17- ACS712 current sensors

18-Digital potentiometer

19-Arduino board

20-ESP32 MCU node

21-Computer

As illustrated by the block diagram in Figure 1, the I-V measurement platform for photovoltaic modules consists of two main parts: the production block and the acquisition block. These two blocks are controlled by a programmable changeover switch that serves as a flip-flop. 


\section{Production block}
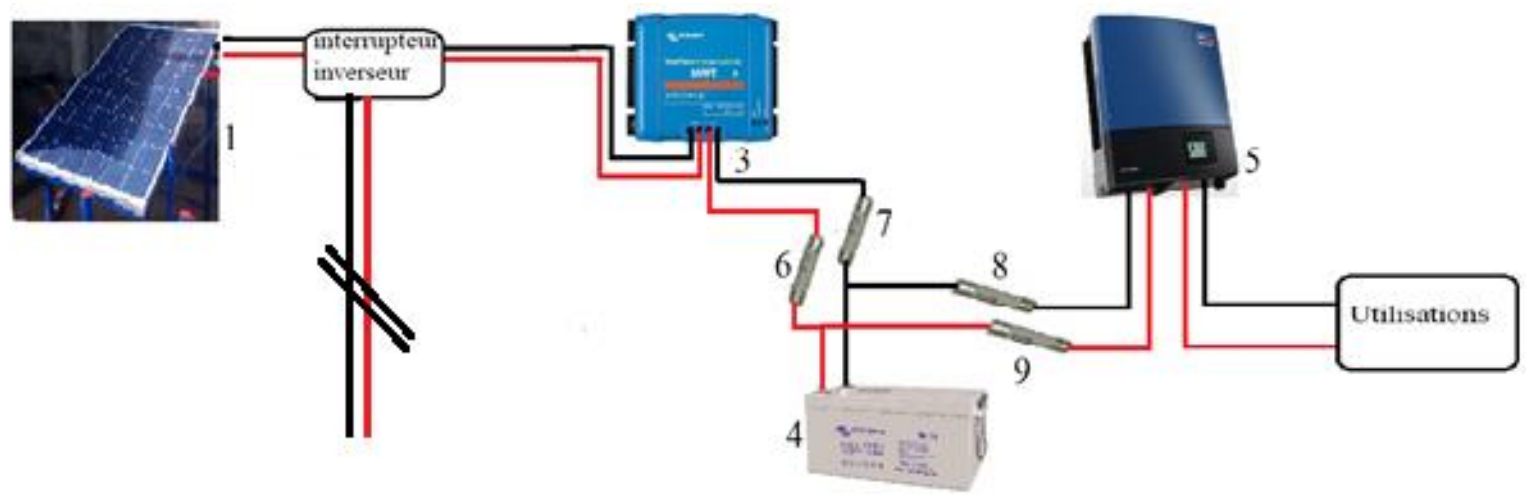

Figure 2: Production block

The production block allowing to feed the laboratory of physics of the Faculty of Sciences and Technologies (FaST), is constituted of:

A small photovoltaic field consisting of four solar modules placed on a metal structure that we have made (Figure 3 ) and installed (Figure 4 and 5) on the roof of the Faculty of Sciences and Technologies.

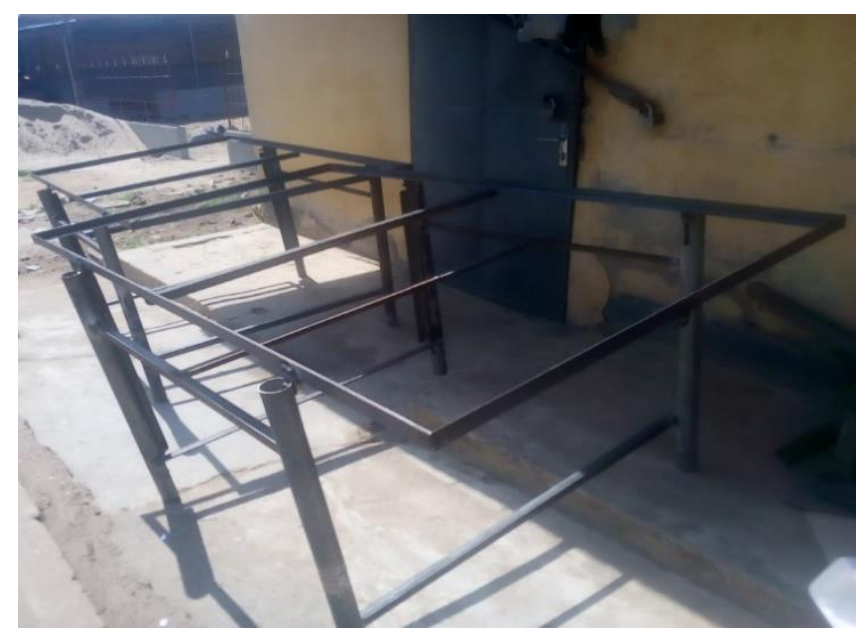

Figure 3:_Assembly of metal structures 


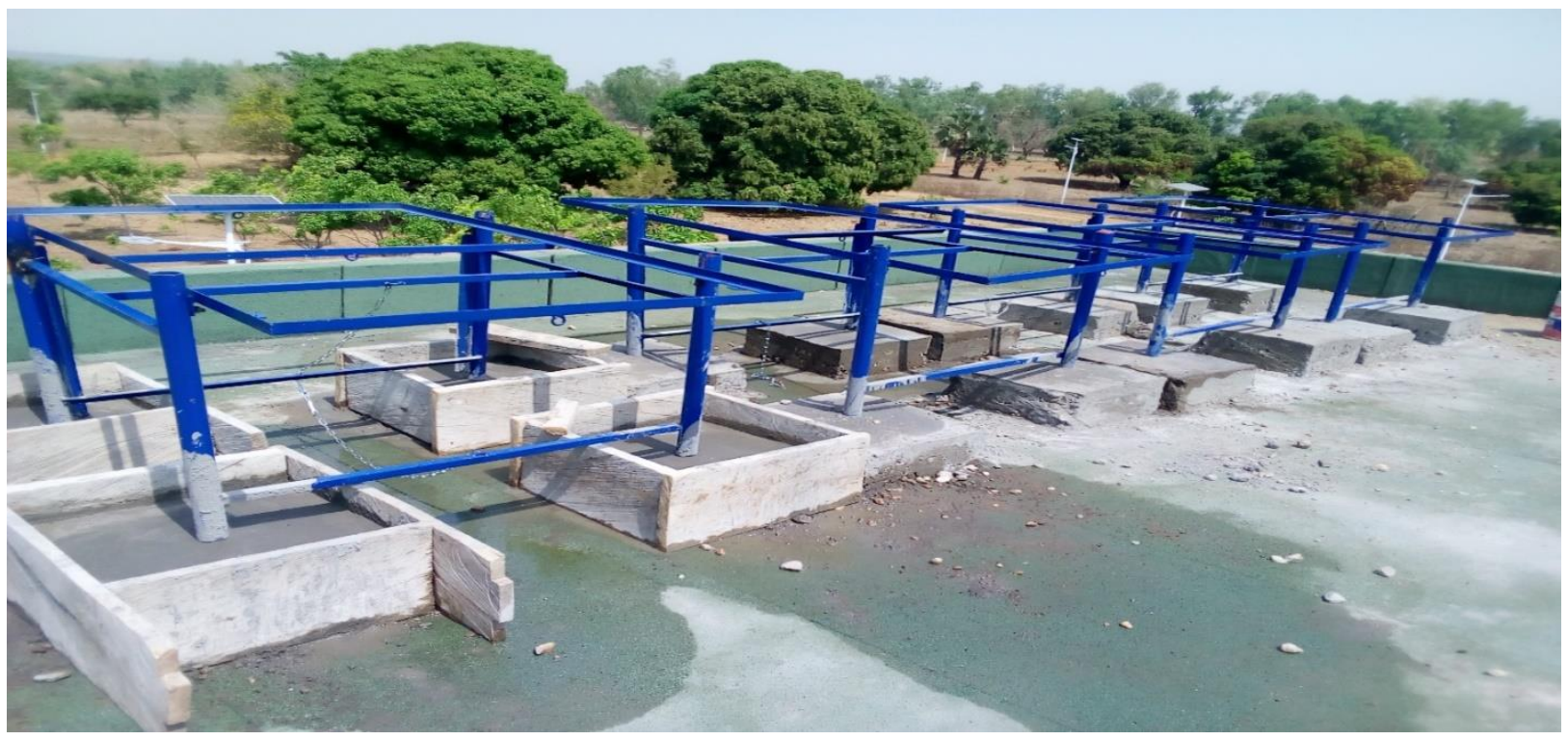

Figure 4: Installation of metal structures

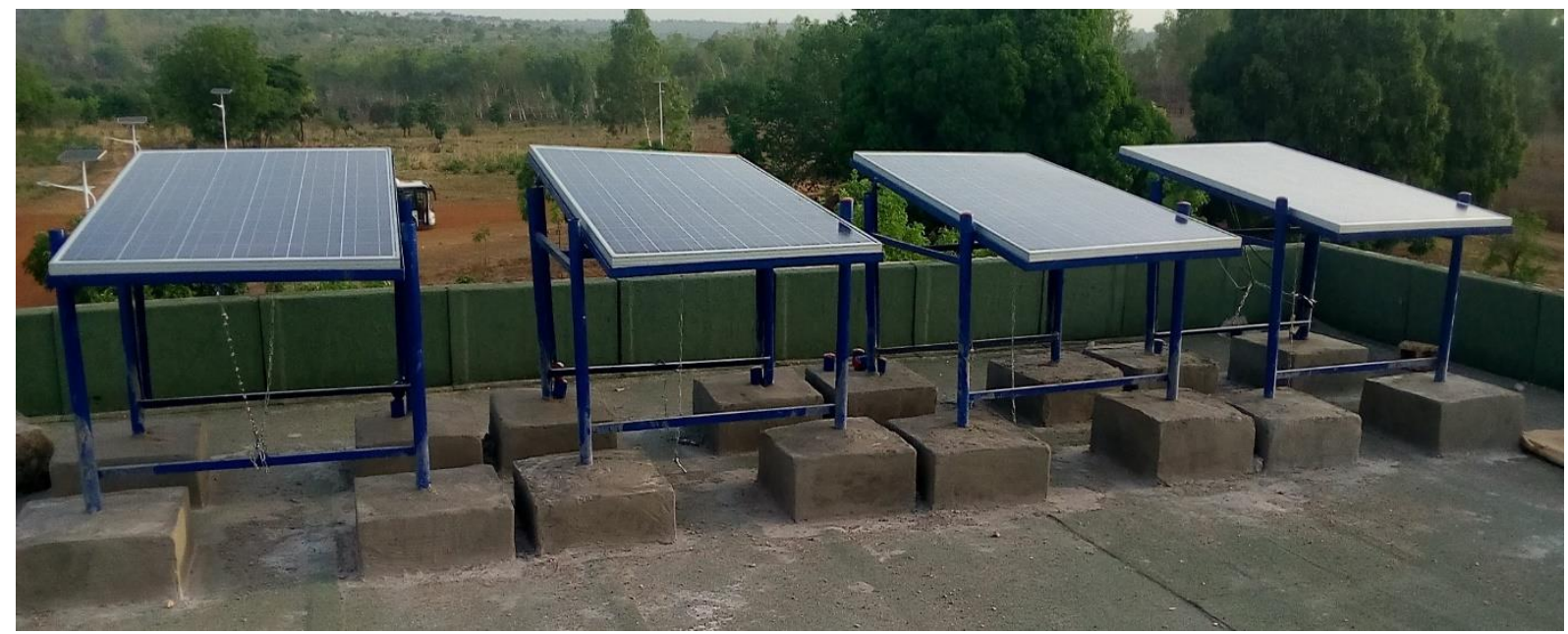

Figure 5: Photovoltaic field installed on the roof of the FaST

- A regulator to control the charge of the batteries and limit their discharge

- Batteries to store energy for times of no sunlight

- An inverter to convert the direct current from the solar modules into alternating current that can be used to power the physics laboratory

\section{Acquisition block}

This block consists of different devices for the measurement of solar irradiation (pyranometer), of the temperature of the modules in operation (temperature probes), of the direction and speed of the wind (wind vane-anemometer), of the ambient temperature and relative humidity (DHT22), of the measurement of the current (ACS712) and of the voltage. For the representation of the I-V characteristic from the current and voltage measurements, it is necessary to vary the impedance in order to have different voltage and current values, hence the usefulness of the digital potentiometer. 


\section{Digital potentiometer}

The characteristics of potentiometers available on the market do not correspond to those of the modules we have for this study, it was therefore important to opt for a variable electronic load.

\section{Electronic load}

Photovoltaic modules are usually tested using direct current electronic loads. These loads are often very expensive. However, with the help of very simple and much cheaper circuits, it is possible to build an electronic load. It varies the resistance over the entire measurement range in a very short time.

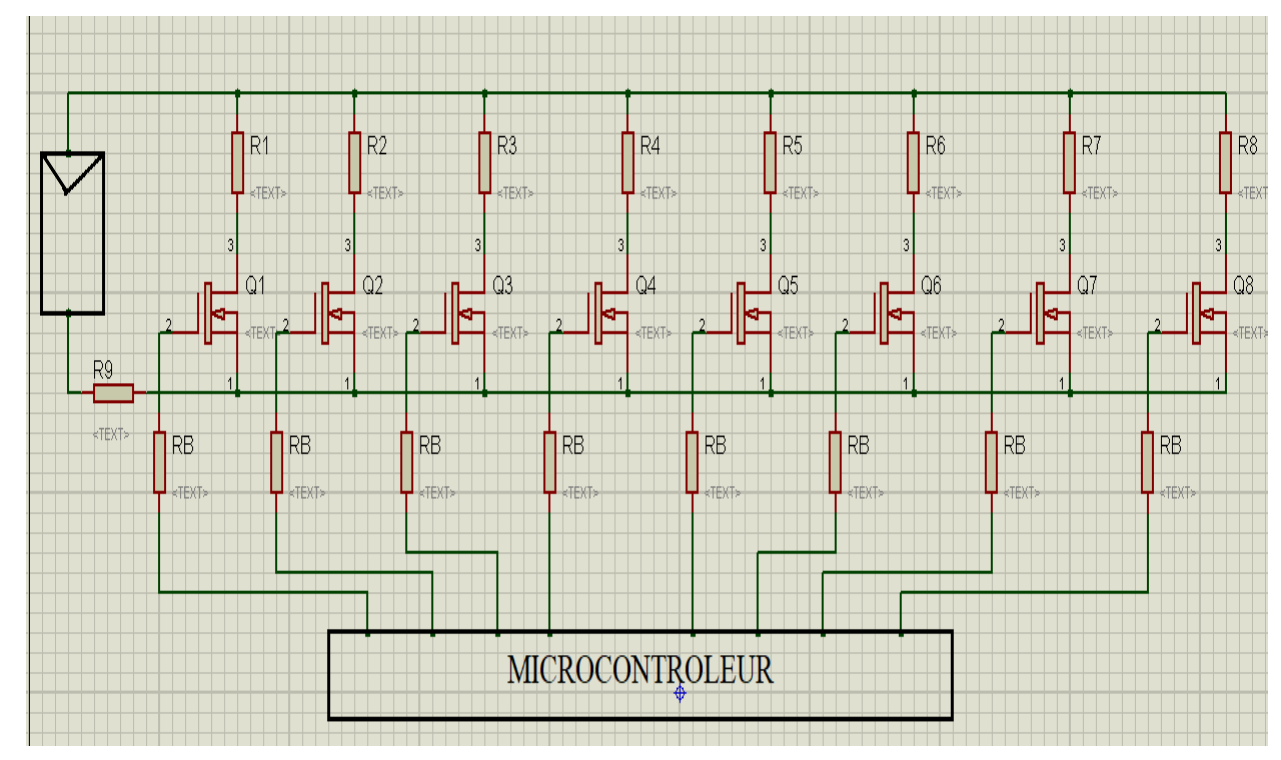

Figure 4: Circuit of the electronic load

For this electronic load, we have connected in parallel resistors that are controlled by a microcontroller that generates control signals. We have used the PIC microcontroller for its efficiency and its availability on the market, to generate the signals that applied to the transistors allow to define the value of the resistance [2]. The MOSFET transistors are chosen for their simplicity, their speed and their lower cost and used in this case as electronic switches.

\section{Data acquisition}

Measurements made by the pyranometer, the vane anemometer, the temperature and humidity sensor, the thermocouples, the temperature sensor, the voltage and current sensors are retrieved by the Arduino board and then transferred to the MCU node. Potentiometers to adjust the periodicity of sending data to the Node MCU, the MAX485 module, a data receiver to transmit the data from the pyranometer to the Arduino, the RTC module, a real time clock to give the time at any time and an LCD screen to display the date, time and ambient temperature are added to allow a better understanding of the data to be acquired. 


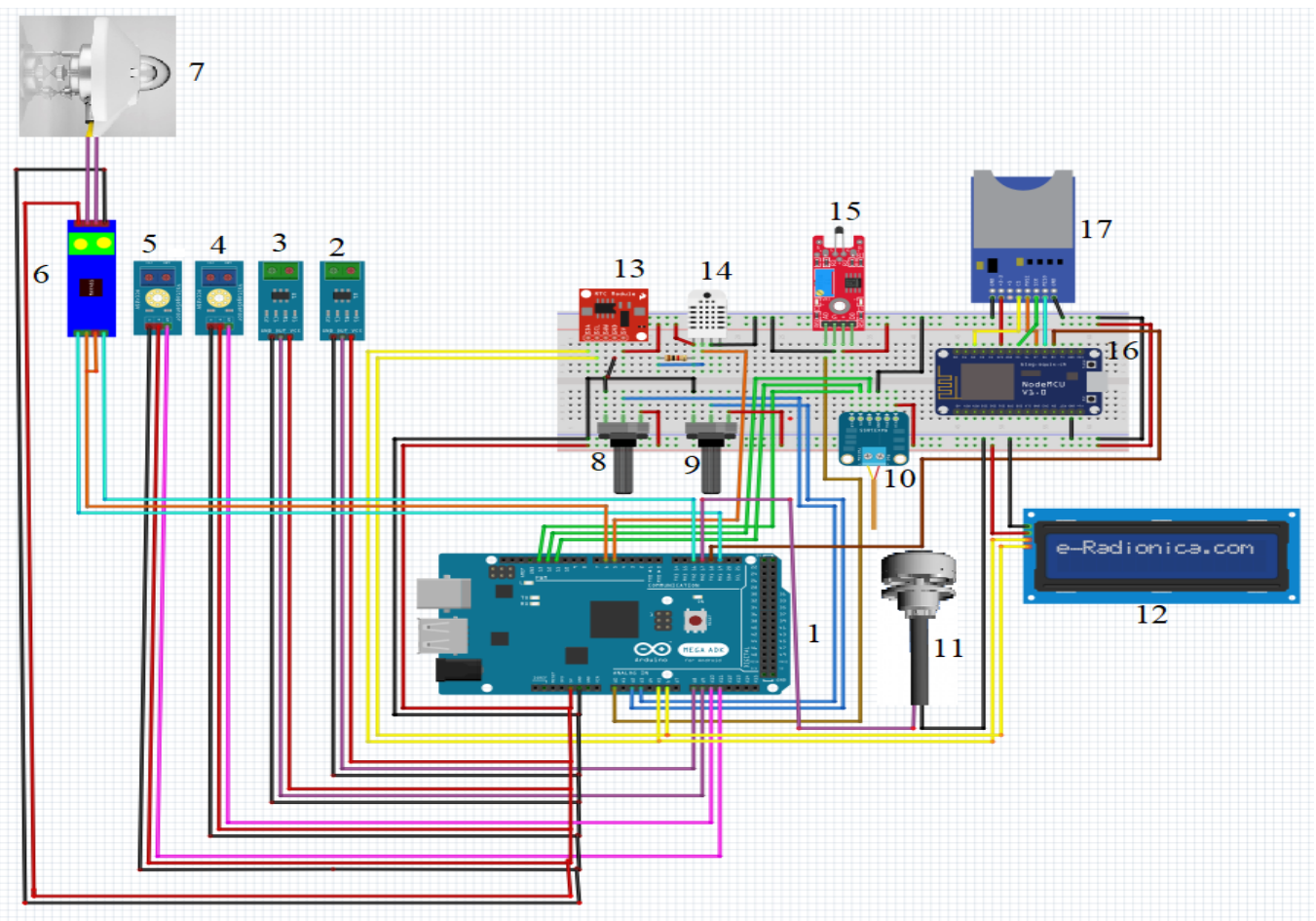

Figure 5: Assembly of the different Arduino sensors

1-Arduino

2,3-Current sensors ACS712

4,5-Voltage sensors

6-Max485 module

7-Pyranometer Temperature sensors

8-9- Potentiometers

10-Thermocouples MAX31855
11- Anemometer- Wind vane

12- LCD screen

13- RTC module

14- DHT22 humidity and temperature sensor

15- Temperature sensor KY-028

16-ESP32 MCU node

17-SD card

In order to acquire the data from the different sensors, we created two programs [3]. A first program that we uploaded on Arduino [4], [5] to recover the measurements made by the different sensors and then transmit them to the Node MCU. The second program is uploaded on the Node MCU allowing it to recover the data, to transfer them on a web server and on a SD card while allowing to download them.

\section{Flowcharts}

The following figure shows the execution steps of the algorithm that we used to develop the programs in C language that we uploaded on the Arduino board and on the Node MCU. 


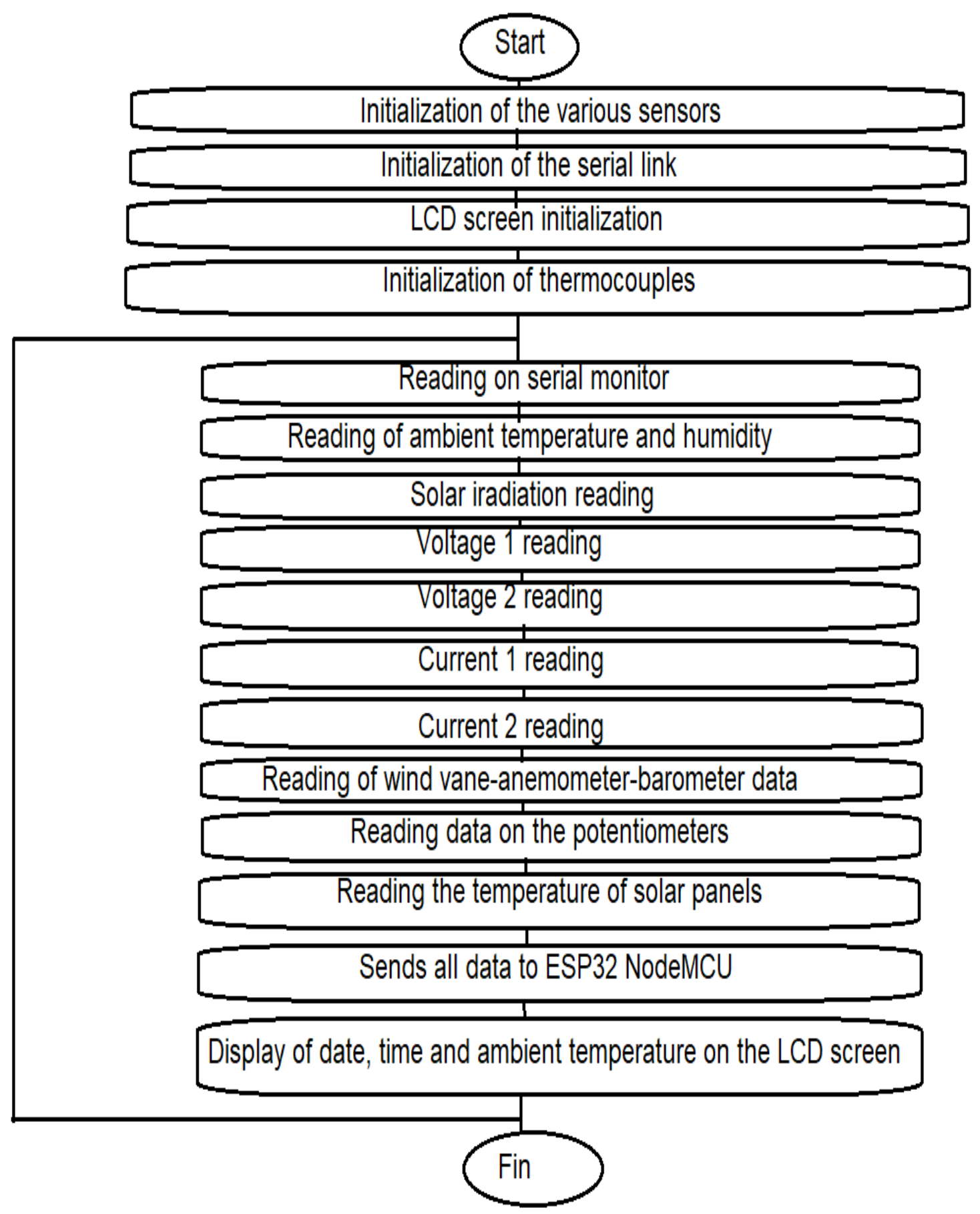

Figure 5a: Flowchart of the program driving the Arduino board 


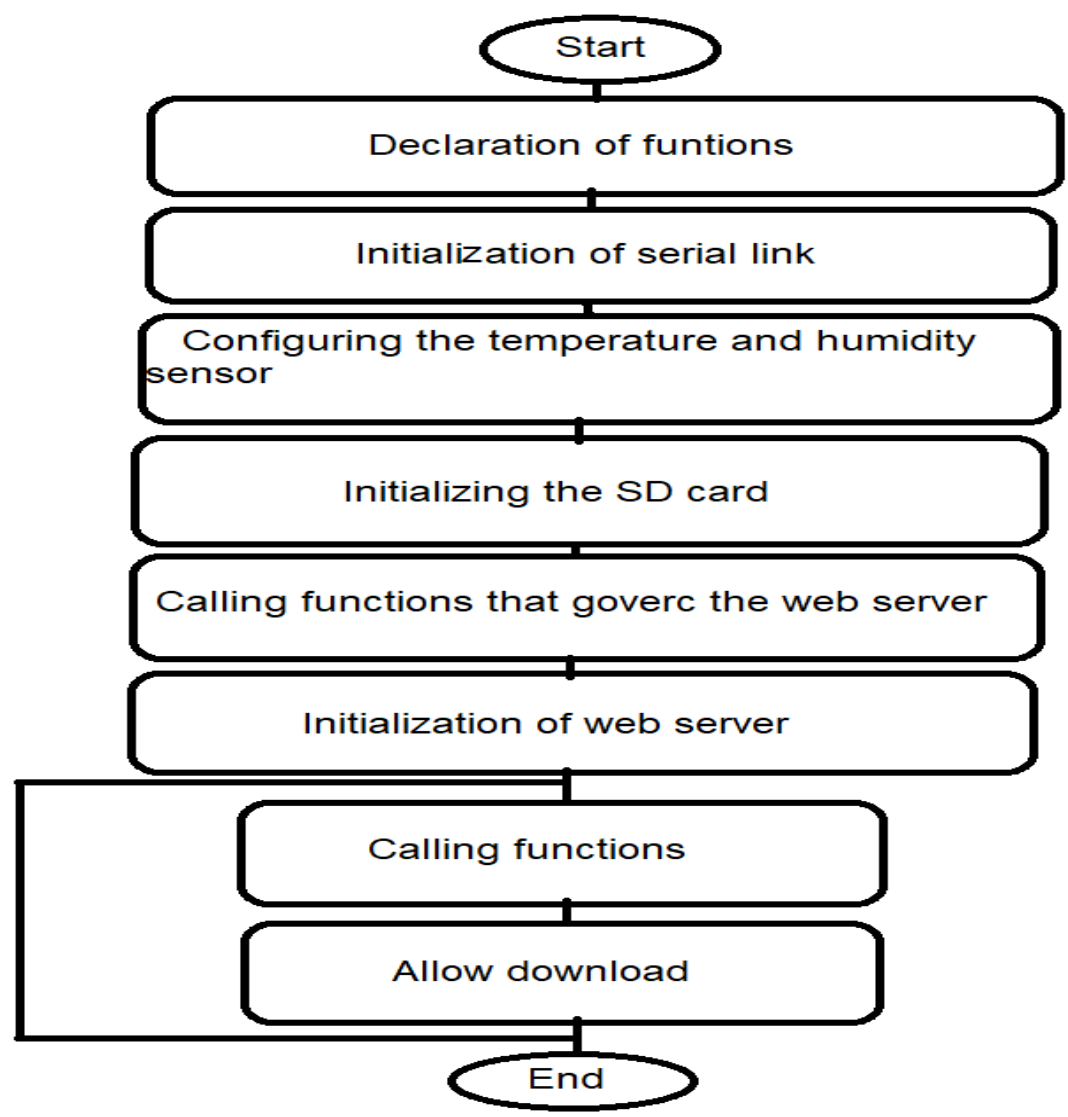

Figure 5 b: Flowcharts of the programs driving the ESP32 Node MCU

\section{Results and discussions}

This project of characterization platform being in progress, in this part, we present only the variation of some climatic parameters according to time. A test was carried out on $26 / 03 / 2021$ from $8 \mathrm{~h} 30$ am to $7 \mathrm{~h} 30 \mathrm{pm}$ on the characterization platform allowing us to present these results.

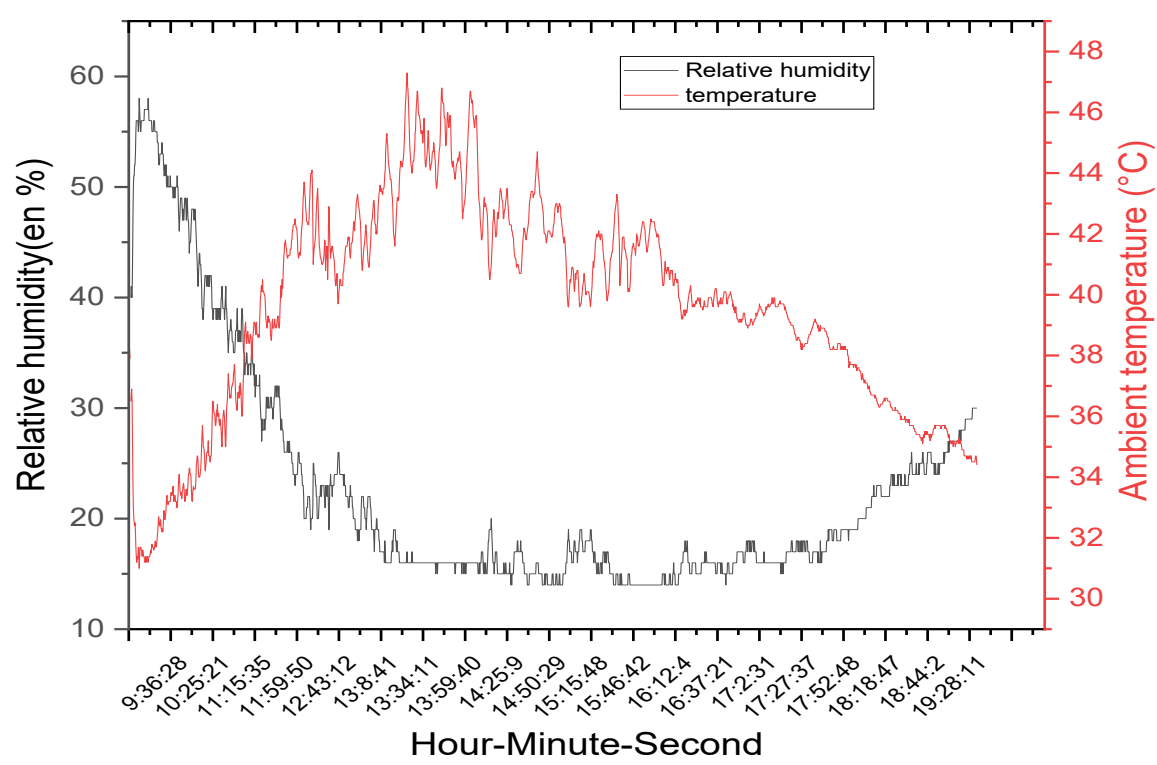

Figure 6 a: Variation of relative humidity and ambient temperature 


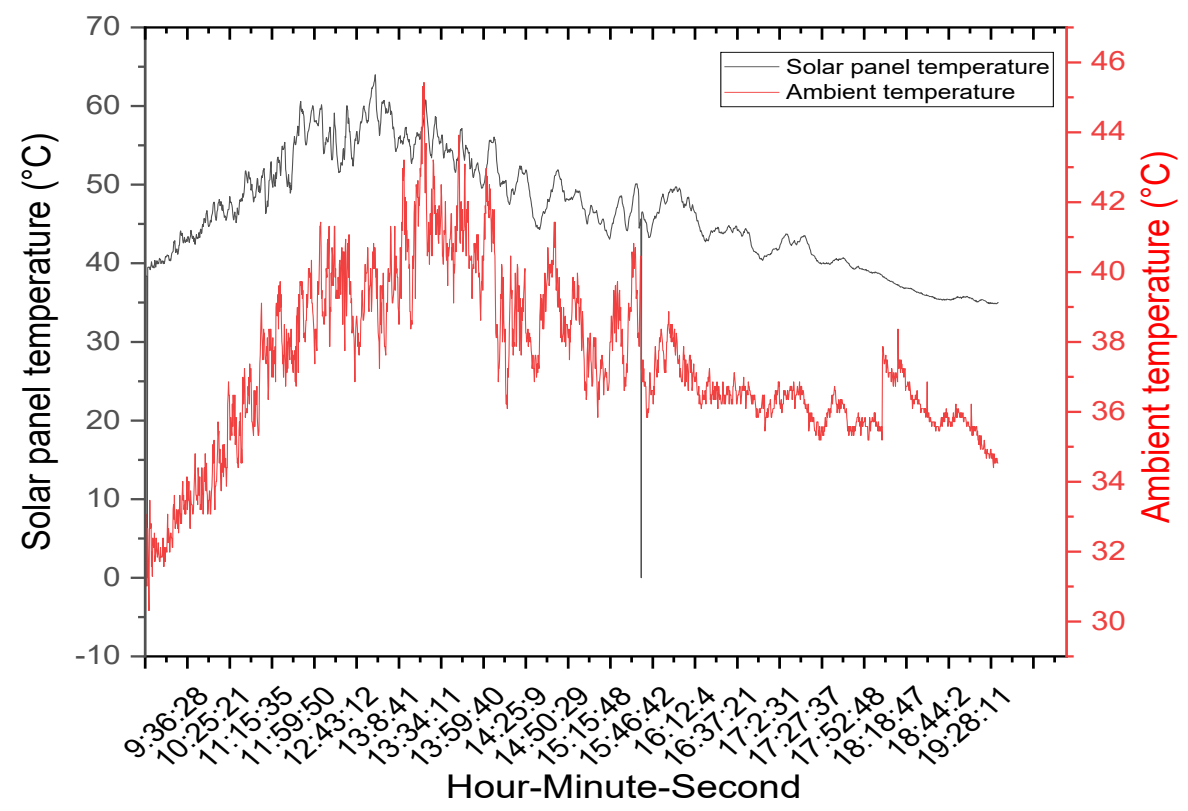

Figure 6b: Variation of the temperature of the solar modules and the ambient temperature

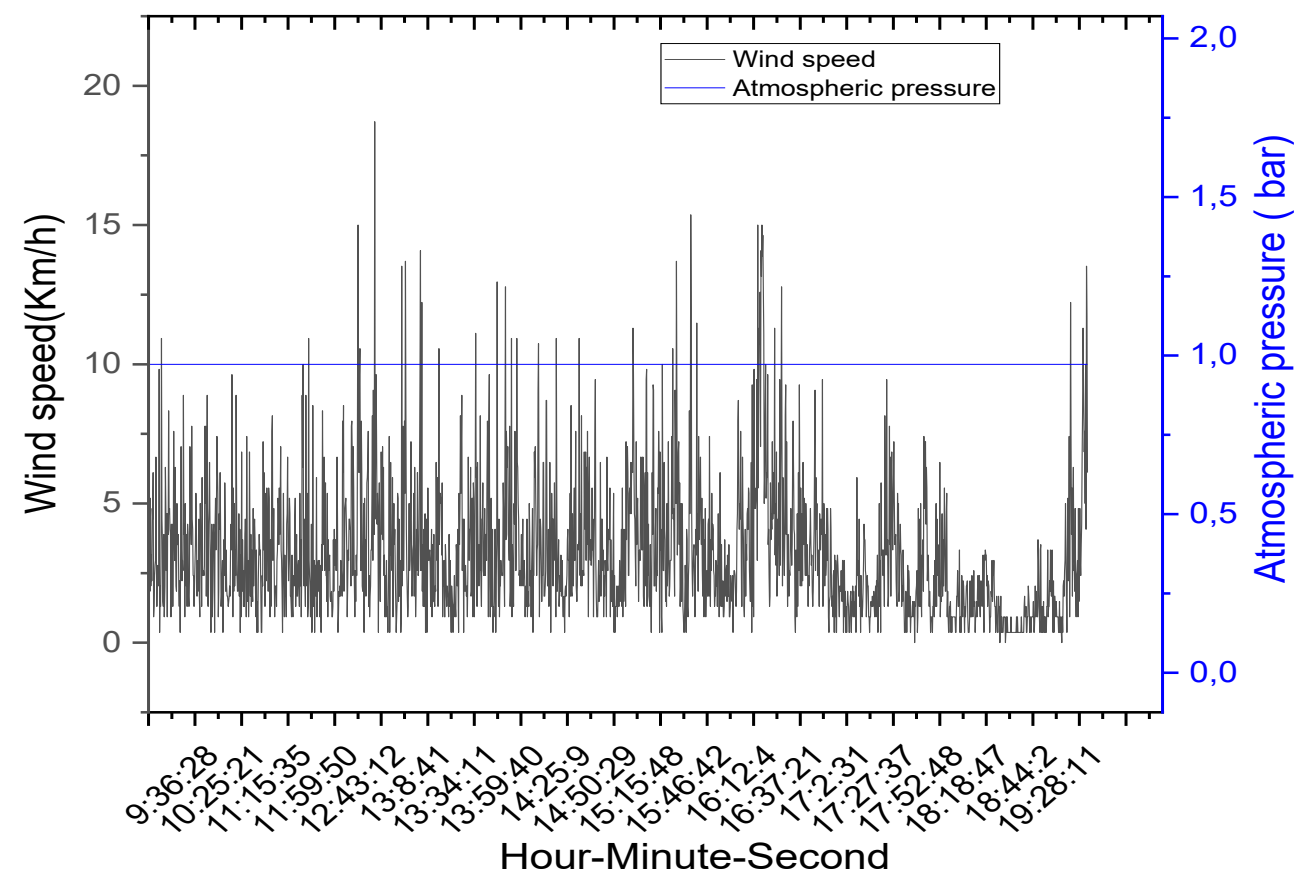

Figure 6c: Variation of wind speed and atmospheric pressure

Figure 6 a shows a decrease in humidity, reaching an almost constant value around $2 \mathrm{pm}$ and starting to increase around $5 \mathrm{pm}$. The ambient temperature increases until it reaches its maximum value around 2:00 pm, a critical time used in the environment for air conditioning projects.

Curve $6 \mathrm{~b}$ shows that the temperature of the modules is generally higher than the ambient temperature during the day because these panels absorb light and heat up.

The atmospheric pressure at the platform site is about 1 bar (Figure 6c), which is roughly equal to normal atmospheric pressure (101.3mbar). The wind speed varies a lot with several 
spikes during this day carrying a lot of dust on the solar modules. The impact of dust will be studied when all the characterization sensors are installed.

\section{Conclusion}

This article presents the work done for the realization of the solar module characterization platform implemented at FaST. Currently, it is possible to acquire meteorological data. However, the work continues in order to acquire the current-voltage characteristics of the solar modules as well as the solar irradiation in order to evaluate the consequences of the effect of the climatic conditions (temperature and dust) on the production of solar modules.

\section{Acknowledgements}

We offer all our recognitions to German Academy Exchange Service DAAD for financially supporting this project through WILDAU University

\section{References}

[1] Asch G, Poussery B. Les capteurs en instrumentation industrielle. 8e édition. Malakoff: Dunod; 2017.

[2] Akoro E, Tevi G, Faye M, Sene M, Maiga A. Modelling and simulation of an automatic solar module characteristics data acquisition system. OAJ Materials and Devices. 2019. https://doi.org/10.23647/CA.MD20191602

[3] Asch G, Néel L. Acquisition de données : du capteur à l'ordinateur. 1 Vol.. 3e édition. Paris: Dunod; 2011.

[4] Nfaoui M, El-Hami K. Conception et réalisation d'un système de métrologie et supervision des paramètres météorologiques et électriques d'une installation photovoltaïque . https://www.openscience.fr//MG/pdf/iste incertfia17v2n5.pdf. 2017;

[5] Tavernier C. Arduino : Applications avancées. Dunod; 2012. 